\title{
Effects of Farmers' Motivation on Their Participation in Publicly Funding Training Programs in Sichuan Province, China
}

\author{
Yurong Zhu' \& Jinxiu Yang ${ }^{2}$ \\ ${ }^{1}$ College of Economics and Management, Sichuan Agricultural University, Chengdu, China \\ ${ }^{2}$ Organization Department, Sichuan Agricultural University, Yaan, China \\ Correspondence: Jinxiu Yang, Organization Department, Sichuan Agricultural University, Yaan 625014, China. \\ Tel: 86-835-288-2128. E-mail: yjx9108@163.com
}

Received: May 21, 2012 Accepted: June 7, 2012 Online Published: August 24, 2012

doi:10.5539/jas.v4n10p68 URL: http://dx.doi.org/10.5539/jas.v4n10p68

\begin{abstract}
Taken Sichuan province, China as target, this paper studied the effect of farmers' motivation on their participation in publicly funding training, and compared the influence before, during and after the training. Results show that effects are there really, autonomous motivation factors (Sense of competence, self-determination, to master the knowledge for self-improvement, to improve one's own skill level) produce significantly positive effects on the different participating stages. However, the controlling motivation factor (have to participate in training for not offending village or township cadres) has significant negative influence on the participation. This paper suggests improving the curriculum setting, training mode and supervision of the current training work, aiming at the feature of farmers' training motivation, thus stimulating the farmers to highly participation in training and improving the effect of public training.
\end{abstract}

Keywords: publicly funding training, motivation, participation, order probit model

\section{Introduction}

Neoclassical economic theory assumes that actors have the self-serving motives. People's pursuit to maximized utility is homogeneous economic rationality with the same preference rules, wisdom and decision-making capacity (Huo, 2007). However, people's specific preferences shown by selecting behavior are variable, personalized, which are closely related to the environment and the behavior of others in the real world (Wang, 2005). Variable preferences, diverse motives and subjective perception will fundamentally change the actual action in many cases (Douglas, 1994).Studies shown that, the behavior motives of economic entities in the decision-making is not exogenously given, but was born in the decision-making process, which leads that economic agents have heterogeneous preferences, while the behaviors with external heterogeneity (Xiong, 2005; Huang, 2007). Therefore, studying the behavior of economic agents from the perspective of motivation has become a noteworthy branch in behavior study.

The "Central First Document" of China has led to the demand for qualified personnel in agricultural and rural economic development since 2004, and the major projects implemented in the agricultural sector and rural areas are continuing to focus on farmer training to meet the need of agricultural strategic structural adjustment and industrial management in China. Local governments are active in organizing and implementing various forms of publicly funded training project. However, contrasting with the high enthusiasm of government is less efficient training, and a low enthusiasm of farmers to participate in training (Wang, 2009). Publicly funded training in rural areas did not give full play to the efficiency and the proper role, in part because of some unobserved variables that force some trainees to participate in the training to a certain extent, who are to curry favor with the organizer or to cope with the task, where the sources of unobserved variables are mainly heterogeneous motivations of the participants. In publicly funded training programs, motivation can influence the decision of trainees investing the energy into training programs (Maurer, 1994). The motivation level of trainers is an important determinant of the effectiveness of training (Rao, 2007). But among those studies, there are lacking studies on the impact of motivation to participation in the training. The majority of them are mainly in analyzing the effect of individual characteristics, family characteristics and socio-economic factors to farmers' willingness participating in the training (Cao, 2005; Wei, 2007; Liu, 2010). Therefore, it is necessary to embark on study on motivation of farmers to participate in the public funding training, which can lay the foundation for the 
development of new farmers' training management, enhance the enthusiasm of farmers to participate in the training, and improve training effects and farmers' participation in training.

Taking farmer technology training plan in Sichuan Province as an example, this paper comprehensively and systematically explored the impact of farmers' motivation on participation in publicly funded training. According to self-determination theory, the farmers' autonomy participation in training is regarded as a dynamic continuum between intrinsic motivation and external regulation in this paper. The motivation is classified as controlled motivation and self-motivation. Controlled motivation includes external adjustment, camera (intake) regulation. Autonomous motivation identified regulation includes integrated motivation and internal motivation (Deci, 1985; Ryan, 2000). This paper will proffer answer to the following questions: Could different types of motives produce different levels of training participation? Which of the motivation factors have positive effect on farmers' high levels participation in training? Which of the motivation factors have negative impact on the farmers' participation?

\section{Conceptual Definition}

Participation is a concept from the field of psychology, which has been widely used in the study of management science (Geng, 2008). Participation is referring to the readiness and degree of subjectivity actors are playing ( $\mathrm{Li}$, 2005). Many scholars defined it from classroom learning and customer behavior (Cermak, 1994; Kellogg, 1997; Li, 2006; Gao, 2006). Farmers training can be taken as a learning process like the traditional classroom teaching as well as a training service, that is, an intangible product. Therefore, combined with previous studies, the paper argues that farmers' participation in training includes the information gathering before the training, the degree of investment in training and the summary evaluation after the training.

Motivation can be defined as those psychological tendencies and internal drive which stimulate and maintain an organism's actions and make them be towards a certain goal. Training motivation is a particular desire or expectation that trainees want to get certain content from the training (Noe, 1986; Tharenou, 2001). Jones (2002) held that training motivation was the tendency, intentions and stable behavior in training. This study suggests that training motivation of farmers refers to the reasons or intentions of whom participate in training.

The paper is organized as follows: the next section describes data sample and variables. Section III discusses the empirical results and the final section summarizes the empirical findings and discusses policy implications.

\section{Data Samples and Variables}

The data in this paper are from a survey of Sichuan province on the autonomy and degree of farmers participating in the Technology Training Plan in August 2010. This survey was conducted on 459 farmers in 11 Cities which include Chengdu, Nanchong, Guangyuan, in Zigong, Neijiang, Ya'an, Meishan, Suining, Deyang, Yibin and Aba, who participated in or were taking part in technology training. After excluding the questionnaires which were answered incompletely or unreliably, there were eventually 452 valid questionnaires. The variables in this paper are from related issues in the questionnaires, while making reference to the previous definition. We will assess the farmers' motivation from themselves point of view.

\subsection{Training Motivation Indicators: Independent Variables}

Farmers training motivation can be measured by how voluntary their behavior is. Self-determination theory states that external motivation, introjective motivation, recognition motivation, integrative motivation and intrinsic motivation is on behalf of a continuum which is changing from a completely external motivation to completely internal motivation. External motivation and introjective motivation belong to controlling motivation. Recognition motivation, integrative motivation and intrinsic motivation belong to autonomous motivation. Sense of competence $\left(\mathrm{X}_{1}\right)$ and self-determination $\left(\mathrm{X}_{2}\right)$ are the center composition of intrinsic motivation. Integrative motivation is driven by the concern of the results of the task. Actors not only identify their own behavior as important, and combine with recognition of self-other aspects. In this paper we use $\mathrm{X}_{3}$ (to master the knowledge for self-improvement) and $\mathrm{X}_{4}$ (to improve one's own skill level) to measure integrative motivation. Recognition motivation is an incentive type that farmers accept the training as self-part when they find the training is important, which $\mathrm{X}_{5}$ (training is very important in life) is used to measure in this paper. Introjective motivation absorbs external rules, which is associated with self-esteem and measured by $\mathrm{X}_{6}$ (do not want to lag behind the others) and $\mathrm{X}_{7}$ (for getting some reward after completing the training). External motivation is measured by $\mathrm{X}_{8}$ (to get the reward so long as involved in training), $\mathrm{X}_{9}$ (have to participate in training for not offending village or township cadres), which is a motivation type for obtaining incidental rewards or meeting external requirements. Each question are assigned an integer of 1-5 to measure farmers' own real idea, which 5 is for "full compliance", 4 is for "basic in line", 3 is for "it is difficult to determine", 2 is for "almost incompatible" and 1 is for 
"completely incompatible".

\subsection{Index of Training Participation: Dependent Variables}

According to the definition of training participation, the dependent variables are represented by $y_{1}, y_{2}, y_{3}$ in this paper, which respectively denotes the time that farmers devotes to gather information before the training, learning in the training and the summary and evaluation after the training. Each variable is assigned a value of 1-5 meaning 'always, most of the time, sometimes, rarely and never' which is respectively used to measure the corresponding time and energy investment. We calculate the overall participation by the arithmetic mean of those three variables and rounding it, which is represented by Y.

\section{Empirical Analysis}

\subsection{Descriptive Statistical Analysis}

Table 1 lists a statistical analysis of the main regression variables, including a set of dependent variables, and 9 independent variables to reflect the farmers' participation motivation.

Table 1. Descriptive statistics of the variables

\begin{tabular}{|c|c|c|c|c|c|c|}
\hline Variables & Defining & $\mathrm{N}$ & Minimum & Maximum & Mean & $\begin{array}{c}\text { Std. } \\
\text { Deviation }\end{array}$ \\
\hline $\mathrm{X}_{1}$ & Sense of competence & 451 & 1 & 5 & 2.35 & .825 \\
\hline $\mathrm{X}_{2}$ & self-determination & 452 & 1 & 5 & 2.00 & .791 \\
\hline$X_{3}$ & to master the knowledge for self-improvement & 452 & 1 & 5 & 2.04 & .928 \\
\hline $\mathrm{X}_{4}$ & to improve one's own skill level & 452 & 1 & 5 & 1.93 & .832 \\
\hline $\mathrm{X}_{5}$ & training is very important in life & 452 & 1 & 5 & 2.51 & .989 \\
\hline $\mathrm{X}_{6}$ & do not want to lag behind the others & 452 & 1 & 5 & 3.43 & 1.116 \\
\hline $\mathrm{X}_{7}$ & for getting some reward after completing the training & 451 & 1 & 5 & 4.33 & .987 \\
\hline $\mathrm{X}_{8}$ & to get the reward so long as involved in training & 452 & 1 & 5 & 4.18 & 1.051 \\
\hline $\mathrm{X}_{9}$ & $\begin{array}{l}\text { have to participate in training for not offending village or township } \\
\text { cadres }\end{array}$ & 450 & 1 & 5 & 4.26 & 1.040 \\
\hline $\mathrm{y}_{1}$ & $\begin{array}{l}\text { the time that farmers devotes to gather information before the } \\
\text { training }\end{array}$ & 452 & 1 & 5 & 3.79 & 1.050 \\
\hline $\mathrm{y}_{2}$ & the time for farmers' learning in the training & 452 & 1 & 5 & 2.78 & 1.215 \\
\hline $\mathrm{y}_{3}$ & The time for making the summary and evaluation after the training & 452 & 1 & 5 & 2.97 & 1.059 \\
\hline $\mathrm{Y}$ & overall participation & 452 & 1 & 5 & 3.18 & .791 \\
\hline
\end{tabular}

The survey on the farmers' participation found that farmers spent less energy to gather related information before the training. Only $11.87 \%$ of farmers were always taking the time to collect training information. $44.18 \%$ of them often spend much time on the interaction in training and $33.48 \%$ often take a lot of time to evaluate after the training.

The comparison between farmers' motivation and participation in publicly funded training can not directly reach the relationship between them. Further regression analysis is needed to test whether the farmers' training motivation impacts their participation in publicly funded training and the extent.

\subsection{Regression Analysis}

\subsubsection{Econometric Model and Coefficient Correction}

The dependent variable is a dummy variable with a certain order, ordered Probit regression model is used to test the effect of farmers' training motivation on their participation. Further, since the regression coefficients of the order Probit regression equation is in form of logarithmic regression coefficients, we do the data processing by $\exp (\mathrm{x})$ to the coefficients for explaining the economics meaning conveniently, which can directly represent the change of growth rate for farmers' participation.

We list Empirical found about the impact of farmers' training motivation on their participation in Table 2. 
Table 2. Ordered Probit regression results on the participation degree against farmers' training motivation

\begin{tabular}{|c|c|c|c|c|c|c|c|c|}
\hline \multirow{3}{*}{$\begin{array}{c}\text { Independent } \\
\text { variables }\end{array}$} & \multicolumn{8}{|c|}{ Regression coefficients, probability changes and significant } \\
\hline & \multicolumn{2}{|c|}{ Y } & \multicolumn{2}{|c|}{$\mathrm{y}_{1}$} & \multicolumn{2}{|c|}{$\mathrm{y}_{2}$} & \multicolumn{2}{|c|}{$\mathrm{y}_{3}$} \\
\hline & $\begin{array}{l}\text { Regression } \\
\text { coefficient }\end{array}$ & $\begin{array}{c}\text { Probability } \\
\text { change }\end{array}$ & $\begin{array}{l}\text { Regression } \\
\text { coefficient }\end{array}$ & $\begin{array}{c}\text { Probability } \\
\text { change }\end{array}$ & $\begin{array}{l}\text { Regression } \\
\text { coefficient }\end{array}$ & $\begin{array}{c}\text { Probability } \\
\text { change }\end{array}$ & $\begin{array}{l}\text { Regression } \\
\text { coefficient }\end{array}$ & $\begin{array}{c}\text { Probability } \\
\text { change }\end{array}$ \\
\hline $\mathrm{X}_{1}$ & $\begin{array}{l}0.141^{* *} \\
(2.07)\end{array}$ & 1.152 & $\begin{array}{c}0.041 \\
(0.61)\end{array}$ & 1.042 & $\begin{array}{l}0.134^{* *} \\
(2.06)\end{array}$ & 1.143 & $\begin{array}{l}0.111^{*} \\
(1.67)\end{array}$ & 1.118 \\
\hline $\mathrm{X}_{2}$ & $\begin{array}{c}0.243^{* * *} \\
(3.08)\end{array}$ & 1.275 & $\begin{array}{l}0.162^{* *} \\
(2.06)\end{array}$ & 1.176 & $\begin{array}{l}-0.060 \\
(-0.81)\end{array}$ & 0.941 & $\begin{array}{c}0.345^{* * *} \\
(4.5)\end{array}$ & 1.411 \\
\hline $\mathrm{X}_{3}$ & $\begin{array}{c}0.082 \\
(1.21)\end{array}$ & 1.086 & $\begin{array}{c}0.042 \\
(0.63)\end{array}$ & 1.043 & $\begin{array}{c}-0.086 \\
(-1.33)\end{array}$ & 0.918 & $\begin{array}{c}0.192^{* * *} \\
(2.91)\end{array}$ & 1.211 \\
\hline $\mathrm{X}_{4}$ & $\begin{array}{l}-0.008 \\
(-0.11)\end{array}$ & 0.992 & $\begin{array}{l}-0.039 \\
(-0.55)\end{array}$ & 0.962 & $\begin{array}{l}0.119^{*} \\
(1.70)\end{array}$ & 1.127 & $\begin{array}{c}-0.04243 \\
(-0.6)\end{array}$ & 0.959 \\
\hline $\mathrm{X}_{5}$ & $\begin{array}{c}0.311^{* * *} \\
(4.83)\end{array}$ & 1.365 & $\begin{array}{l}0.149^{* *} \\
(2.35)\end{array}$ & 1.161 & $\begin{array}{c}0.327^{* * *} \\
(5.25)\end{array}$ & 1.387 & $\begin{array}{l}0.134^{* *} \\
(2.17)\end{array}$ & 1.143 \\
\hline$X_{6}$ & $\begin{array}{l}0.091^{*} \\
(1.8)\end{array}$ & 1.095 & $\begin{array}{l}0.041 \\
(0.83)\end{array}$ & 1.042 & $\begin{array}{l}-0.022 \\
(-0.45)\end{array}$ & 0.978 & $\begin{array}{c}0.199^{* * *} \\
(4.00)\end{array}$ & 1.220 \\
\hline $\mathrm{X}_{7}$ & $\begin{array}{l}0.173^{* *} \\
(2.26)\end{array}$ & 1.189 & $\begin{array}{c}0.099 \\
(1.31)\end{array}$ & 1.104 & $\begin{array}{l}0.150^{* *} \\
(2.03)\end{array}$ & 1.161 & $\begin{array}{c}0.083 \\
(1.11)\end{array}$ & 1.086 \\
\hline $\mathrm{X}_{8}$ & $\begin{array}{l}0.155^{* *} \\
(2.32)\end{array}$ & 1.168 & $\begin{array}{l}0.165^{* *} \\
(2.52)\end{array}$ & 1.179 & $\begin{array}{c}0.026 \\
(0.41)\end{array}$ & 1.027 & $\begin{array}{c}0.056 \\
(0.85)\end{array}$ & 1.057 \\
\hline $\mathrm{X}_{9}$ & $\begin{array}{l}-0.160^{* *} \\
(-1.97)\end{array}$ & 0.853 & $\begin{array}{l}-0.114 \\
(-1.42)\end{array}$ & 0.892 & $\begin{array}{l}-0.143^{*} \\
(-1.84)\end{array}$ & 0.867 & $\begin{array}{l}-0.055 \\
(-0.71)\end{array}$ & 0.946 \\
\hline $\begin{array}{c}\text { chi spuare } \\
\text { (18) }\end{array}$ & & & & & & & 13 & .55 \\
\hline Prob > chi 2 & & & & & & & 0. & \\
\hline
\end{tabular}

\subsubsection{Analysis of Regression Results}

The regression results show that farmers' motivation significantly affect their participation in the publicly funded training. Their autonomy motivations significantly improve the training participation. Among the controlling motivations, the variable $\mathrm{X}_{9}$ (have to participate in training for not offending village or township cadres) has a significant negative impact on farmers' participation. Other controlling variables still bring some extent on the participation.

(1) The impact of motivation on overall participation

Autonomous motivation factors including $\mathrm{X}_{1}$ (competence) and $\mathrm{X}_{2}$ (self-determination), $\mathrm{X}_{5}$ (training is very important in life) affect farmers' overall participation. If these variable values generate an additional unit, the growth rate of farmers' overall participation in the publicly funded training would increase at least 1.152, 1.275, and 1.365 respectively. According to educational psychology, interest is an inner strength promoting people seeking knowledge, and therefore farmers with autonomous motivation have higher participation in publicly funded training. Those participating the training for competence or a better life are bound to pay more efforts to achieve the target, thus improving training participation.

Controlling motivational factors including $\mathrm{X}_{6}$ (do not want to lag behind the others), $\mathrm{X}_{7}$ (for getting some reward after completing the training), $\mathrm{X}_{8}$ (to get the reward so long as involved in training) and $\mathrm{X}_{9}$ (have to participate in training for not offending village or township cadres) affect farmers' overall participation. For the first three variables, if these variable values generate an additional unit, the growth rate of farmers' overall participation in the publicly funded training would improve at least 1.095, 1.189, 1.168 respectively and vice versa. The regression results of $\mathrm{X}_{6}$ verified the explanation of social interaction theory for limited participation. The impact of $X_{7}$ on farmers' training participation is greater than $X_{8}$, which is not difficult to understand. If the farmers' motivation is just get the reward and they can get the reward definitely the instant that they participate in the training, they often just gather the information before training and the effort during the training is unimportant for them. However, if the reward can be gotten only when farmers completed the task which organizers set in advance, they have to takes energy to seriously study and evaluate for reaching the task ultimately, and then 
participation of this kind of training will naturally be higher than the former. If $X_{9}$ increases by one unit, the growth rate of farmers' overall participation will decline at least 0.853 . The found is concordant with the result of Wang (2009). According to the survey, because of the improper training management, it is not a voluntary choice for many farmers to participate in training. Most of them are forced to do it for not offending village or township cadres. This kind of training will naturally not to arouse farmers' enthusiasm for learning, and their training participation decreases subsequently.

(2) The impact of motivation on information-gathering before training

Autonomous motivation factors including $\mathrm{X}_{2}$ (self-determination) and $\mathrm{X}_{5}$ (training is very important in life) affect farmers' information-gathering before training. If these variable values generate an additional unit, the growth rate of farmers' information-gathering degree before the publicly funded training would increase at least $1.176,1.161$ respectively. This finding suggests that farmers have the momentum to search for training teachers, institutions and other relevant information, when their purpose is to master the training content or improve the quality of life.

$\mathrm{X}_{8}$ (to get the reward so long as involved in training) is the main controlling motivation factor affecting farmer to gather training information. In agreement with the earlier analysis, farmers will spend time on searching for the information about the training location, time or prizes contents before the training just for getting the reward. The training participation motivation like this can not help or even have a negative effect to improve training effect.

(3) The impact of motivation on energy investment during the training

Autonomous motivation factors including $\mathrm{X}_{1}$ (competence) and $\mathrm{X}_{5}$ (training is very important in life) affect farmers' energy investment during the training. If these variable values generate an additional unit, the growth rate of farmers' energy investment degree during the publicly funded training would increase at least 1.143 , 1.387 respectively. Consistent with the analysis of overall participation, the energy investment degree during training improved by these two motivation can radically enhance the effectiveness of publicly funded training.

$\mathrm{X}_{7}$ (for getting some reward after completing the training) and $\mathrm{X}_{9}$ (have to participate in training for not offending village or township cadres) is the main controlling motivation factor affect farmer to invest energy during training. There is a certain role in promoting the training effect for the energy investment increased by such a motivation, but it needs a very high reward. If $\mathrm{X}_{9}$ increase by one unit, the growth rate of farmers' energy investment degree will decline at least 0.867 .This finding suggests that those who participated in the training merely for not offending village or township cadres, have no motility to study seriously during the publicly funded training.

(4) The impact of motivation on evaluation degree after the training

Autonomous motivation factors including $X_{1}$ (competence) and $X_{2}$ (self-determination), $X_{3}$ (to master the knowledge for self-improvement) impact farmers' evaluation degree. If these three variable values generate an additional unit, the growth rate of farmers' evaluation degree after the publicly funded training would increase at least $1.118,1.411$, and 1.143 respectively. Obviously the self-determination of these three motivations is very strong. Farmers with these motivations want to learn new knowledge from the heart. Making summary and evaluation after the training has a great influence to farmers' decision for the next participation in similar training.

$\mathrm{X}_{6}$ (do not want to lag behind the others) is the main controlling motivation factor affecting farmer to make summary and evaluation after the training. If $\mathrm{X}_{6}$ increase by one unit, the growth rate of farmers' evaluation degree will improved at least 1.220. Farmers with this motivation will evaluate whether themselves are in the same horizontal line or better than others.

\section{Conclusions and Policy Recommendations}

\subsection{Conclusions}

Based on the survey data in August 2010, this paper studied the impact of farmers' training motivation on their participation in publicly funded training, while comparing the influence during the different participation stages. The empirical results show autonomous motivation produces significantly positive effects on the different participation stages, however, some controlling motivation factors have significant negative influence on the participation. The main motivation factors impacting farmers' training participation are different in the different participation stages. It is found that farmers can participate in the publicly funding training actively and effectively only when they are on their own volition. 


\subsection{Policy Recommendations}

The findings in this paper not only provide empirical support for the influence of heterogeneous motivation on the behavior decision-making which is neglected by the existing literatures, but also gave an important basis for the management of education project for comprehensive quality of farmers . To better play the role in improving the diathesis of peasants, and promoting rural economy, this paper proposed the following policy suggestions.

\subsubsection{Optimize the Training Courses}

The training department should optimize training courses both in difficulty and usable. On one side, too difficult training content will curb farmers' competent motivation and decrease their participation, which is bad to the training effect. At present, farmers' knowledge-level is somewhat low universally in China. The training course should be as easy as possible for considering fully the farmers' learning ability. The other side, the survey shows, most farmers are eager for improving their life level through training. In other words, if the training content is truly practical, which has the substantive function on improving their life, the farmers' participation will be higher and the training effect will be remarkable along with it. Therefore, practically considering the usability of training course and clearing the training goal will have significant effect on improving the training effect.

\subsubsection{Innovate the Training Ways}

Empirical results show that the autonomous motivation has remarkable positive influence on improving farmers' training participation. But in actual training, the majority training forms are sole and arid (mainly are classroom teaching), which are hard to arouse farmers' interest. So we should effectively use farmers' interest motivation to build a good and positive training environment by innovating and reforming the training ways to a wide range, paying more attention to practice and improving the operability and interactive of the training.

\subsubsection{Strengthen Training Supervisions and Assessment Mechanism}

Currently, the related departments assess the publicly funding training agency mainly based on its training population, which neglected the training quality supervision. Many training classes only care about how many person attend, not considering what the farmers' really need, which causes massively farmers participating in training for the motivation of 'to get the reward so long as involved in training' or ' for not offending village or township cadres'. That does not help for achieving the expectation effect of training. Therefore, it is one of the good ways for improving the training effect to strengthen the omni-directional supervision to training organizations from the areas of making training information known to public, announcing the audit result, assuring pellucidity of the training processes and allowing social people to supervise.

On the other hand, many farmers participated in training only for obtaining the rewards and subsidy, which reflects that the current training mechanism is not perfect to a certain extent. So the training departments should establish the unified and standardized graduation inspection procedure, strengthen the supervision and inspection during the process of assessing certificate and the subsidy issuance.

\section{Acknowledgements}

This paper is part of the research achievement of the National Social Science Funding Project of China "The implementation effect of publicly funding employment training in ethnic minorities' rural areas (NO. 11BGL064)".Thanks for the support of Sichuan Statistical Research project "The development of characteristic agriculture industry in Sichuan Province" the same.

\section{Reference}

Cao, J., Hu, R., \& Huang, J. (2005). Influencing factors of farmers' willingness to participate in technical training and adopt new technologies. China Soft Science, 6, 60-66.

Charles, R. (1979). Economic theory of choice and the preference reversal phenomenon. American Economic Review, 4, 623-638.

Cermak, D. S. P., File, K. M., \& Prince, R. A. (1994). Customer Participation in Service Specification and Delivery. Journal of Applied Business Research, 2, 90-97.

Dec, E. L., \& Ryan, R. M. (1985). Intrinsic motivation and self-determination in human behavior. New York: Plenum, 38-39.

Douglas, C. N. (1994). Institutions, institutional change and economic performance. Shanghai Joint Publishing Press, 25-28.

Gao, C., \& Xu, J. (2006). Experimental study of students participating degree in Physical Education Teaching of Middle School. China School Physical Education, 8, 28-30. 
Grether, David, M., Plott, \& Geng, X. (2008). Measurement of customers involving dimensions, driving factors and the mechanism of customer satisfaction. Zhejiang University, Dissertation for Ph.D degree.

Huang, Z., \& Yu, N. (2007). Study of factors affecting farmers' training willingness and countermeasures discussion. Journal of Zhejiang University (Humanities and Social Sciences), 3, 35-42.

Huo, J., Na, Y., \& Dong, J. (2007). Individual motivations and behavioral economics. Comparative Economic \& Social Systems, 3, 12-18.

E.g Jones, J. E. (2002). Self-determination Theory as a Model for Motivation in a Training Context. Unpublished Ph.D thesis Department of University of Oklahoma, American.

Kellogg, D. L., Youngdahl, W. E., \& Bowen, D. E. (1997). On the relationship between customer participation and satisfaction: two frameworks. International Journal of Service Industry Management, 3, 206. http://dx.doi.org/10.1108/09564239710185406

Li, X., \& Li, B. (2005). Study of the teaching mainstay's participating degree. Research in Teaching, 3, 8-11.

Li, Y. (2006). Improve students' participating degree in mathematics teaching. Central China Normal University, Dissertation for Master degree.

Liu, F., Yang, J., \& Yang, Q. (2010). Analysis of farmers' training willingness and influencing factors case of Sichuan Province, China. Journal of Sichuan Agricultural University, 1, 105-109.

Maurer, T., \& Tarulli, B. (1994). Investigation of Perceived Environment, Perceived Outcome, and Person Variables in Relationship to Voluntary Development Activity by Employees. Journal of Applied Psychology, 1, 3-14. http://dx.doi.org/10.1037/0021-9010.79.1.3

Noe, R. A. (1986). Trainees'Attributes and Attitudes: Ne-glected Influences on Training Effectiveness. The Academy of Management Review, 4, 736-749. http://dx.doi.org/10.5465/AMR.1986.4283922

Rao, W., \& Xiao, M. (2007). The analysis of civil servants' training participating motivation. Management World, 10, 57-64.

Ryan, R. M., \& Deci, E. L. (2000). Self-determination and the facilitation of intrinsic motivation, social development, and well-being. American Psychologist, 55, 68-78. http://dx.doi.org/10.1037/0003-066X.55.1.68

Tharenou, P. (2001). The Relationship of Training Motivations to Participation in Training and Development. Journal of Occupational and Organizational Psychology, 11, 599-622.

Wang, G., Huang, T., \& Ge, X. (2005). The heterogeneity of economic behavior and the development of experimental economics. Economic Research Journal, 11, 125-128.

Wang, H., Huang, S. H., \& Li, Q. (2009). The impact of vocational skills training on farmers' nonfarm income. Economic Research Journal, 9, 128-140.

Wei, L., \& Ruan, J. (2007). The influencing factors analysis of Peri-urban farmers participating in quality training. Chinese Rural Economy, 3, 32-37.

Xiong, H. (2005). Consumption habits, heterogeneous preferences and dynamic asset pricing. Economic Research Journal, 10, 91-100. 